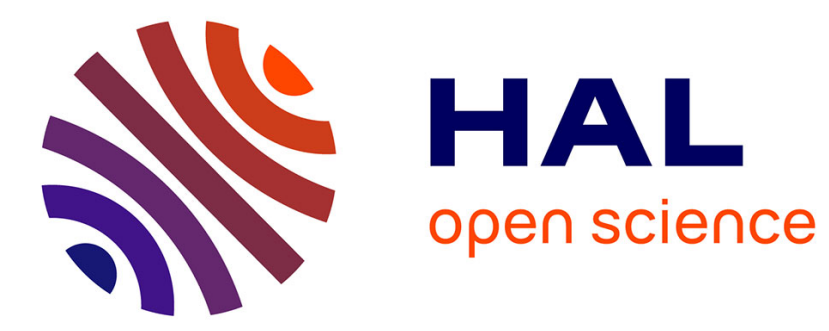

\title{
What Next for Digital Himalaya? Reflections on Community, Continuity, and Collaboration
}

Mark Turin

\section{To cite this version:}

Mark Turin. What Next for Digital Himalaya? Reflections on Community, Continuity, and Collaboration. Verge: Studies in Global Asias, 2018, 4 (2), pp.57-63. 10.5749/vergstudglobasia.4.2.0057 . halshs-03083463

\section{HAL Id: halshs-03083463 \\ https://shs.hal.science/halshs-03083463}

Submitted on 27 Jan 2021

HAL is a multi-disciplinary open access archive for the deposit and dissemination of scientific research documents, whether they are published or not. The documents may come from teaching and research institutions in France or abroad, or from public or private research centers.
L'archive ouverte pluridisciplinaire HAL, est destinée au dépôt et à la diffusion de documents scientifiques de niveau recherche, publiés ou non, émanant des établissements d'enseignement et de recherche français ou étrangers, des laboratoires publics ou privés. 
What Next for Digital Himalaya? Reflections on Community, Continuity, and Collaboration

\section{Author(s): Mark Turin}

Source: Verge: Studies in Global Asias, Vol. 4, No. 2 (Fall 2018), pp. 57-63

Published by: University of Minnesota Press

Stable URL: https://www.jstor.org/stable/10.5749/vergstudglobasia.4.2.0057

JSTOR is a not-for-profit service that helps scholars, researchers, and students discover, use, and build upon a wide range of content in a trusted digital archive. We use information technology and tools to increase productivity and facilitate new forms of scholarship. For more information about JSTOR, please contact support@jstor.org

Your use of the JSTOR archive indicates your acceptance of the Terms \& Conditions of Use, available at https://about.jstor.org/terms

University of Minnesota Press is collaborating with JSTOR to digitize, preserve and extend access to Verge: Studies in Global Asias 


\section{What Next for Digital Himalaya? Reflections on Community, Continuity, and Collaboration}

SEVENTEEN YEARS AGO, in December 2000, a group of four anthropologists and historians at the University of Cambridge set out to explore new methods for collecting, protecting, and connecting historical multimedia collections relating to the Himalayan region in ways that would widen access to the materials through emerging digital platforms. Sarah Harrison, Alan Macfarlane, Sara Shneiderman, and I named this pilot project "Digital Himalaya." We began by digitizing older sets of ethnographic data held in university and personal collections across Europe to protect them from obsolescence and decay, forward migrate them as new standards emerged, and share them back with originating communities in the Himalayan region and with scholars everywhere through the web and other digital media, as appropriate. ${ }^{1}$

The process, challenges, early successes, and ethical quandaries-not to mention the steps involved in selecting the original collections for digitization, the process of curation, the frequency of updates, and the necessary international collaboration that ensued-have been the topic of a number of academic and popular articles (cf. Shneiderman and Turin 2002; Turin 2011, 2012, 2015) and are beyond the scope of this contribution. In this short piece, appropriately framed within the Interface feature, I wish to explore the changing demographic of our users, the constructive criticism and welcome attention that we have received for the work in which we are engaged, the shifting expectations about what services and role we provide, and some reflections around the future of this collaborative partnership. The analytical backdrop to this article is my growing sense of unease about the sustainability of digital projects, an 
unease shared by other commentators working with new media in the digital realm. In their important 2014 volume Re-collection: Art, New Media, and Social Memory, museum professionals Richard Rinehart and Jon Ippolito ask readers to reflect on how increasingly digital forms of civilization will persist beyond our lifetimes and argue that the vulnerability of new media art illustrates a larger crisis for social memory. Rinehart and Ippolito's proposed "variable media approach" to new media, with responsibilities distributed between producers and consumers, "encourages creators to define a work in medium-independent terms so that it can be translated into a new medium once its original format is obsolete" (11). Over the past seventeen years, as new standards and possibilities have emerged, I have come to the conclusion that if the digitized content and material collections with which we have worked are "safe," then the structure that holds them together can be permitted to decay as new platforms take their place. In this, then, Digital Himalaya may be a simple object lesson in impermanence and nonattachment to form and structure, letting go of our now quite dated website so that the collections may live on through a generative process of rebirth and renewal.

\section{AUDIENCE DEMOGRAPHICS: CHANGING EXPECTATIONS}

When we established the project in 2000, we naively imagined that we were building a web portal primarily for academic users in the Global North who would have unfettered access to the internet through fast broadband networks and that communities in the Himalayas would be better served by us burning the digitized collections onto DVDs and depositing hard copies with institutes, colleges, and universities across Asia. How wrong we were!

Ever since we started tracking visits to and downloads from our website in 2005, a strikingly different pattern has emerged. Of the more than five hundred thousand unique "sessions" that Google Analytics has recorded, 19 percent have been from Nepal, 16 percent from the United States, 10 percent from India, and 8 percent from the United Kingdom. It is particularly satisfying that almost one hundred thousand web users in Nepal have accessed our content, offering a comprehensive challenge to our early assumption in 2000 that the "West" would have the web and the "Rest" would have hard discs and DVDs. Similarly striking are the data provided by Google about device category. While of the half million hits that the site has received since we started to track in 2005, only 9 percent have been on mobile devices and 2 percent have been on tablets, with the remainder from desktop or laptop computers; the use of handheld devices to access Digital Himalaya content has increased dramatically over time. 
In the last year alone (July 2016-2017), mobile devices accounted for 20 percent of all visits and tablets for 4 percent, and given the increasing penetration of ${ }_{3} \mathrm{G}$ mobile services across the Himalayan region, we can only expect this trend to increase in the coming years. At the same time, we receive as many requests from institutions in the Global North for offline copies of our collections on hard discs as we do from scholarly institutes in the Himalayan region. Some of our heaviest users download PDFs and films from our website using solar or hydropowered satellite broadband internet connections in Himalayan locations that would traditionally be described as "remote," as they have no vehicular access and/or are not on the national electricity grid.

\section{CRITIQUES OF THE APPROACH}

Over the years, Digital Himalaya has received its fair share of critical scholarly attention from archivists, librarians, museum curators, and fellow anthropologists who have explored both the potential and the limitations of our approach. Social sciences subject librarian at the Binghamton University Libraries Anne Larrivee $(2013,46)$ observes that while the "collections provide a unique array of culturally-enlightening digital resources on the Himalayan region," the "content is setup in an organizationally-limited way" and the "site feels like a pathfinder to available resources rather than a research tool to link to specific data." While we have worked closely with staff in libraries, archives, and museums, we acknowledge that none of our core project members are information management professionals, and this has led to limitations in our interface and organization. Other scholars have found more to praise in our applied approach, including archaeologist Sudeshna Guha (2012, 43), who suggests that Digital Himalaya "continues to remain theoretically useful for probing into relationships between digital replications and productions of cultural knowledge," and anthropologist Gina Drew (2012, 682), who suggests that Digital Himalaya's "efforts in resource sharing and collaborative publishing serve as a model for future endeavors to keep anthropological materials, from working papers to unedited video clips and field notes, in the public domain." All of these critiques and commendations are important and welcome and help us to refine, design, and look toward new opportunities for the project.

\section{WHAT IS DIGITAL HIMALAYA? CHANGING EXPECTATIONS}

As the project has aged and the internet has matured, I have been interested to observe a slowly changing perception of what Digital Himalaya is and how it works. Is it an archive? If so, by whom is it curated, and by 
what standards and selection process are materials included or excluded for dissemination? Or is Digital Himalaya more of an archive of an archive, a constantly mutating and transmigratory "collection of collections" that could never have been brought into conversation with one other than through a web interface. It has become clear to many of us working in this space that digital media impact both the subject and the tools of archival practice (Rinehart \& Ippolito, 2014: 232).

By web standards, we are now an old project, designed and built before Google was a household name, when $4 \mathrm{MB}$ downloads were still large and all of our project team accessed our shared file folder through dial-up modems. While we have redesigned the website on a number of occasions, and have increased the size of our media collections as bandwidth has increased, I cannot escape the awkward feeling that our entire collection and approach are still rooted in an earlier, less interactive, and more traditional era of web technology. A large amount of the correspondence that we receive in the project e-mail inbox comes from scholars looking to publish in one of the many journals that we host online, even though we make it quite clear on our website that we are simply the online hosts, not editors or publishers. But as digital publishing has become the norm, and the front-end delivery of academic content becomes more widespread through open access initiatives, perhaps we are fulfilling part of the role of publisher, if only through dissemination, so this conflation of roles is to be expected.

As search tools have become more effective and more pervasive, we find that our collections are located, accessed, and downloaded without the user ever visiting or even knowing about our website. A simple search for a map, some census data, or a publication from the Himalayan region may send a prospective user to one of our file servers, bypassing the loose architecture of our website altogether. Whereas some technologists would perceive this as a problem, we view it as an asset: the visibility and discoverability of the collections hosted by Digital Himalaya have now reached the point that they no longer requires the fabric of our original website to facilitate access. It is striking how much you can achieve if you don't need or wish to take credit for it.

Similarly, we have opted for a redundancy approach to our multimedia collections, which are now housed on Cambridge University streaming servers, on the University of Virginia Tibetan and Himalayan Library, and also on YouTube. Not only is YouTube a very popular site for streaming video but it facilitates the very interaction, feedback, and commentary (in any number of languages) to which we originally aspired and which our own, much more basic website does not permit. Our thinking about the 
importance of our own interface has changed as standards have emerged over time and as some media-sharing sites have come to dominate the market. No longer are we allocating resources to developing sophisticated search and retrieval systems or pages that house images or audio and video collections, but we are rather focusing on pushing our content and the associated metadata to the places and platforms where they are most visible and best utilized. This is indicative of a wider reorientation among some digital projects that are moving away from developing customized and curated interfaces to collections of content to a "broadcasting" approach that makes use of free, albeit commercial, platforms to reach the widest possible audience.

\section{THE DIGITAL FUTURE: BUILDING TOWARD SUSTAINABILITY}

Sustainability for digital projects comes in various forms, with the two primary types being financial and technical. On the financial side, the project has turned away from relying on funding from research councils and foundations to a looser, flatter model of support from donations of time and money and some minimal advertising revenue generated through Amazon referrals and YouTube advertisements. I am sympathetic to colleagues who view such an approach as "selling out" but would remind them that open access is not free and that resources for servers, updates, and the digitization of new collections need to come from somewhere. While I don't believe that the micropayments from huge technology companies will float Digital Himalaya in the long term, I do think that it's worth experimenting with, if only because Digital Himalaya was always imagined to be a creative exploration of potential. While the project has done well in applying for and receiving operational grants, all of which are outlined and recognized online, ${ }^{2}$ we have never had the comfort of core funding or institutional support on which to fall back.

The other primary vulnerability built into our system was institutional insecurity. Although Alan Macfarlane was an established professor at the University of Cambridge, the other three team members had relationships to the university that were more attenuated and less permanent. We often asked ourselves what the implications were of building a digital multimedia repository at a university to which only one of us had an enduring connection. Once again, time has proven to be an ally in our process. Our early commitment to DSpace, the University of Cambridge institutional repository, as the technical backbone for all of our collections provided deep security as two of our core team moved around the world on limited-term academic appointments. Now that Shneiderman 
and Turin have settled at the University of British Columbia (UBC), where both are tenured faculty, we have started to explore Digital Himalaya's next incarnation. Fortunately, UBC also uses the DSpace platform as its institutional repository, and I recently oversaw the bulk export of the entire Digital Himalaya collection from the Cambridge servers to a hard disc to enable its importation into UBC's Open Collections portal as a Featured Collection. ${ }^{3}$ Following this data migration, which is planned for academic year 2017-2018, we believe that Digital Himalaya will finally be secure. While our current website may in time be retired, the collections that we have helped to digitize will have a new and permanent online home. As Rinehart and Ippolito (2014, 233) note, "new media works are going to need to be managed and migrated on a continual basis." Rather like the phoenix of ancient Greek mythology, I have now come to understand that Digital Himalaya will be cyclically regenerated and reborn, gaining new life by rising from the ashes of its earlier incarnation. And I have had to accept that the digital is just as transient, evanescent, and inconstant as other forms of analogue or corporeal existence.

Mark Turin ( $\mathrm{PhD}$, linguistics, Leiden University, 2006) is an anthropologist, linguist, and occasional radio presenter and an associate professor of anthropology at the University of British Columbia (UBC). From 2014 to 2018, Turin served as chair of the First Nations and Endangered Languages Program, and from 2016 to 2018, he was acting codirector of the university's new Institute for Critical Indigenous Studies. Before joining UBC, Turin was an associate research scientist with the South Asian Studies Council at Yale University and the founding program director of the Yale Himalaya Initiative. He continues to hold an appointment as visiting associate professor at the Yale School of Forestry and Environmental Studies. Turin directs both the World Oral Literature Project, an urgent global initiative to document and make accessible endangered oral literatures before they disappear without record, and the Digital Himalaya Project, which he cofounded in 2000 as a platform to make multimedia resources from the Himalayan region widely available online. Turin is the author or coauthor of four books and three travel guides and the editor of eight volumes, and from 2013 to 2017 , he served as coeditor of the journal HIMALAYA. Turin also edits a series on oral literature with Open Book Publishers and is a regular $\mathrm{BBC}$ presenter on issues of linguistic diversity and language endangerment. He tweets @markturin. 


\section{NOTES}

The author is grateful to Charlotte Eubanks, Pasang Yangjee Sherpa, and the external reviewers, who all provided welcome and substantive suggestions on ways to improve this short contribution. All remaining errors and infelicities are my own.

1. See the Digital Himalaya Project "Overview" page for more information: http://www.digitalhimalaya.com/overview.php.

2. See http://www.digitalhimalaya.com/support.php.

3. https://open.library.ubc.ca.

\section{WORKS CITED}

Drew, Georgina. 2012. "Digital Himalaya and the Collaborative Publishing Experience.” American Anthropologist 114, no. 4: 680-81.

Guha, Sudeshna. 2012. "Curating Data, Disseminating Knowledge: $\mathrm{Mu}-$ seums in the Digital Age." In Proceedings ECLAP 2012: Conference on Information Technologies for Performing Arts, Media Access, and Entertainment, edited by Paolo Nesi and Raffaella Santucci, 41-45. Florence: Firenze University Press.

Larrivee, Anne. 2013. "Digital Himalaya Project." Reference Reviews 27, no. 2: 45-46.

Rinehart, Richard, and Jon Ippolito. 2014. Re-collection: Art, New Media, and Social Memory. Cambridge, Mass.: MIT Press.

Shneiderman, Sara, and Mark Turin. 2002. "Digital Himalaya: An Ethnographic Archive in the Digital Age." In Interarchive: Archival Practices and Sites in the Contemporary Art Field, edited by Beatrice von Bismarck et al., 359-61. Köln: Buchhandlung Walter König.

Turin, Mark. 2011. "Born Archival: The Ebb and Flow of Digital Documents from the Field." History and Anthropology 22, no. 4: 445-6o.

Turin, Mark. 2012. "Salvaging the Records of Salvage Ethnography: The Story of the Digital Himalaya Project.” Book 2.0 1, no. 1: 39-46.

Turin, Mark. 2015. "The Unexpected Afterlives of Himalayan Collections: From Data Cemetery to Web Portal." In The Anthropology of Expeditions: Travel, Visualities, Afterlives, edited by Joshua A. Bell and Erin L. Hasinoff, 242-68. Chicago: University of Chicago Press. 